\title{
Renal organogenesis
}

\section{What can it tell us about renal repair and regeneration?}

\author{
Melissa H. Little \\ Institute for Molecular Bioscience; The University of Queensland; Brisbane, QLD Australia
}

Key words: kidney development, regenerative medicine, stem cells, lineage, renal repair

Abbreviations: bm, bone marrow; BrdU, bromodeoxyuridine; CFU-F, colony-forming unit-fibroblastic; Cre, Cre recombinase; GFP, green fluorescent protein; GUDMAP, genitourinary development molecular atlas project; HSC, haematopoietic stem cell; LacZ, $\beta$-galactosidase encoding gene; MET, mesenchyme to epithelial transition; MM, metanephric mesenchyme; MSC, mesenchymal stem cell/mesenchymal stromal cell; RV, renal vesicle; UB, ureteric bud; UUO, unilateral ureteric obstruction

Submitted: 09/10/11

Accepted: 09/12/11

http://dx.doi.org/10.4161/org.7.4.18057

Correspondence to: Melissa H. Little;

Email: M.Little@imb.uq.edu.au
$\mathrm{T}$ he increasing prevalence of chronic kidney disease in the absence of new treatment modalities has become a strong driver for innovation in nephrology. An increasing understanding of stem cell biology has kindled the prospects of regenerative options for kidney disease. However, the kidney itself is not a regenerative organ, as all the nephrons are formed during embryonic development. Here, we will investigate advances in the molecular genetics of renal organogenesis, including what this can tell us about lineage relationships, and discuss how this may serve to inform us about both the normal processes of renal repair and options for regenerative therapies.

\section{Introduction}

Chronic kidney disease is a growing problem worldwide, with an annual increase in incidence of $8 \% .^{1}$ As of 2008 , treatment and management of patients with end-stage renal disease cost in excess of $\$ 39$ billion per annum and resulted in $>88,000$ deaths annually in the US. ${ }^{2}$ The US also has one of the highest incidences of chronic kidney disease in the world, second only to Taiwan, although many other developing nations show a similar trend toward increases in incidence of renal disease, which is closely associated with increases in rates of diabetic nephropathy. ${ }^{1,2}$ In Australia, as in the US, diabetes has now overtaken glomerulonephritis as the leading cause of chronic kidney disease. While rates of kidney disease are increasing, the modalities of treatment remain largely unchanged. Patients are either treated via organ transplantation or dialysis. Hemodialysis only provides $10-15 \%$ of the normal glomerular filtration rate, is expensive to deliver and still has a high rate of mortality $(20.8 \%$ in the US in 2008). ${ }^{2}$ Fewer than 1 in 4 patients in the US will receive a renal transplant despite a $>4$-fold increase in the number of transplantations performed per annum since 1980 and the increasing use of live donors over cadaveric organs. Transplant recipients receive a high quality of renal function but must remain on immunosuppressants to overcome chronic rejection, and graft survival at 10 years is around $50 \% .^{2}$

The combination of lack of access to organs, deficiencies in dialysis and an increasing patient population has provided a strong impetus to seek alternative strategies for the treatment of chronic kidney disease. We have previously proposed that renal therapeutic options that could be considered would encompass the spectrum of therapeutic options being investigated for other organs. ${ }^{3}$ These would include either improvements in organ repair or de novo organ regeneration. Within organ repair, one might envisage a spectrum of options, including in situ repair, either via the delivery of reparative growth factors, the recruitment of stem cells from distant sites, such as the bone marrow, or the stimulation of endogenous stem cell populations. The concept of de novo organ regeneration in the kidney is a challenging one given the cellular complexity of this organ and the tight architectural constraints on structure to ensure proper renal function. However, as for other organs in which bioengineering approaches are being attempted, the options here would 
include either the bioengineering of a device to replace or substitute for nephron activity or the bioengineering of an entire replacement organ. ${ }^{3}$

Any of these approaches will rely upon the level to which we understand how the organ forms in the first place, from where the component cell types arise and how these cells are able to respond to different challenges. In other organs, notably the hematopoietic system, a substantial body of understanding exists with respect to component cell types, specific markers for the identification and isolation of these populations, their lineage relationships, repopulating capacities and response to injury. A need for a similar level of understanding in the kidney was recognized by the NIDDK, who responded via the initiation of the Genitourinary Development Molecular Anatomy Project (GUDMAP), the objective of which was to catalog temporospatial gene expression in the developing urogenital tract of the mouse in order to completely catalog the cell types present, the genes that mark these cells, the regulatory factors required to induce or maintain such cells and the developmental and anatomic relationships of each cell type to its neighbor across time. ${ }^{4,5}$

\section{What do We Know about Kidney Development and Lineage Relationships?}

The permanent mammalian kidney is the metanephros. These paired organs arise from two intermediate mesoderm-derived cell populations; an epithelial ureteric bud, which grows out from the metanephric duct, and the metanephric mesenchyme (MM). ${ }^{6,7}$ Outgrowth of the ureteric bud toward the adjacent MM results from the production of glial-derived neurotrophic factor (Gdnf) by the MM, which is transduced via binding to the Ret receptor tyrosine kinase being expressed on the ureteric bud cells. ${ }^{7}$ The ureteric bud (UB) grows toward the MM before undergoing an initial branching event (E11 in the mouse). Subsequent predominantly dichotomous branching forms the ureteric tree, which will ultimately specialize into the collecting ducts and ureter of the kidney. Just as the UB cells respond to ligand from the MM, the MM is induced by the UB to condense around the tips of the forming branched ureteric epithelium and to undergo a mesenchyme-to-epithelial transition (MET) to form renal vesicles. ${ }^{6,7}$ These small epithelial structures immediately begin to pattern as they proliferate and elongate to form the nephrons. ${ }^{6,7}$ The process of MET is triggered via canonical Wnt signaling initiated by the secretion of Wnt9b from the ureteric tip, ${ }^{8,9}$ which in turn upregulates Fgf8 and Wnt4..$^{10,11}$ Noncanonical Wnt4 signaling, in turn, initiates renal vesicle formation. ${ }^{12,13}$

While we have been aware of these interactions for some 50 years, ${ }^{14}$ our understanding of the molecular basis of these events and the lineage relationships between different cell types in the kidney has increased dramatically in the last decade (Fig. 1). We now know that the $\mathrm{Osr}^{+}$intermediate mesoderm gives rise to the MM, ${ }^{15}$ and while the nephron epithelia arise from the MM, ${ }^{16,17}$ this is also the source of many other cell types, including interstitial elements, such as the perivasculature mesangial cells and possibly also a portion of the renal endothelium. The nephron-forming portion of the MM that condenses around the tips of the advancing ureteric tree is referred to as the cap mesenchyme. A number of transcription factors mark the cap mesenchyme and lineage tracing studies ${ }^{16,17}$ have revealed that this Six $2^{+}$Cited $1^{+}$population of mesenchymal cells does give rise to all the epithelial cell types of the nephron, with the exception of the collecting ducts (derived from the ureteric epithelium). Six 2 appears to be a critical molecule in the self renewal of this nephron progenitor/stem cell population, as loss of Six 2 results in premature loss of this cellular compartment due to differentiation. ${ }^{18}$

\section{Anchor Genes for Specific Cellular Compartments}

While we know that once a renal vesicle is formed, there is extensive patterning and segmentation to form the specific tubular regions and their functionally critical cell types, our understanding of lineage relationships after the cap mesenchyme is still lacking. Identification of genes specifically expressed in a single spatial cellular compartment during kidney development was one of the major aims of our research within GUDMAP (www.gudmap.org). As an initial approach to the identification of marker genes, an atlas of gene expression during kidney development was generated based upon microarray gene expression analysis. ${ }^{19}$ Using laser capture microdissection, 15 distinct anatomical compartments of the developing kidney were isolated, including a number of distinct portions of the developing nephron. Affymetrix gene expression profiling was then performed for each anatomical compartment. The specificity of each compartment was validated by bioinformatic selection of enriched gene sets, with this revealing the segregation of existing marker genes with the appropriate anatomical region. Section in situ hybridization also supported the quality of this analysis. ${ }^{19}$

While many genes show relative differences in the level of expression in different cellular compartments, we proposed that the most valuable gene sets that we could identify from this data set were those where genes showed absolute compartment specificity. We defined such genes as "anchor genes" and selected potential anchor genes based on bioinformatics (Fig. 2).$^{20}$ Such genes will be invaluable as leads for the development of GFP:Cre mice to facilitate further compartment isolation and characterization as well as lineage tracing. Potential anchor genes were identified from within the Brunskill et al. data with subsequent validation again employing high-resolution section in situ hybridization of E15.5 mouse kidneys (Fig. 2). From 200 potential candidates, we have thus defined a total of 37 anchor genes marking a total of six anatomical subcompartments in kidney development, including early proximal tubule, loop of Henle, medullary collecting duct, renal corpuscle, renal vesicle and ureteric tip. ${ }^{20}$ Of note, 25 of these anchor genes were expressed in early proximal tubule (Fig. 2) and included genes involved in epithelial differentiation and proximal tubular function, particularly solute channel genes (Slc22a6, Slc18a1, Slc27a2, Slc3a1, Slc6a20b) and Aqp11. An analysis of the minimal promoters of these proximal tubular genes revealed evidence for common transcriptional regulation 


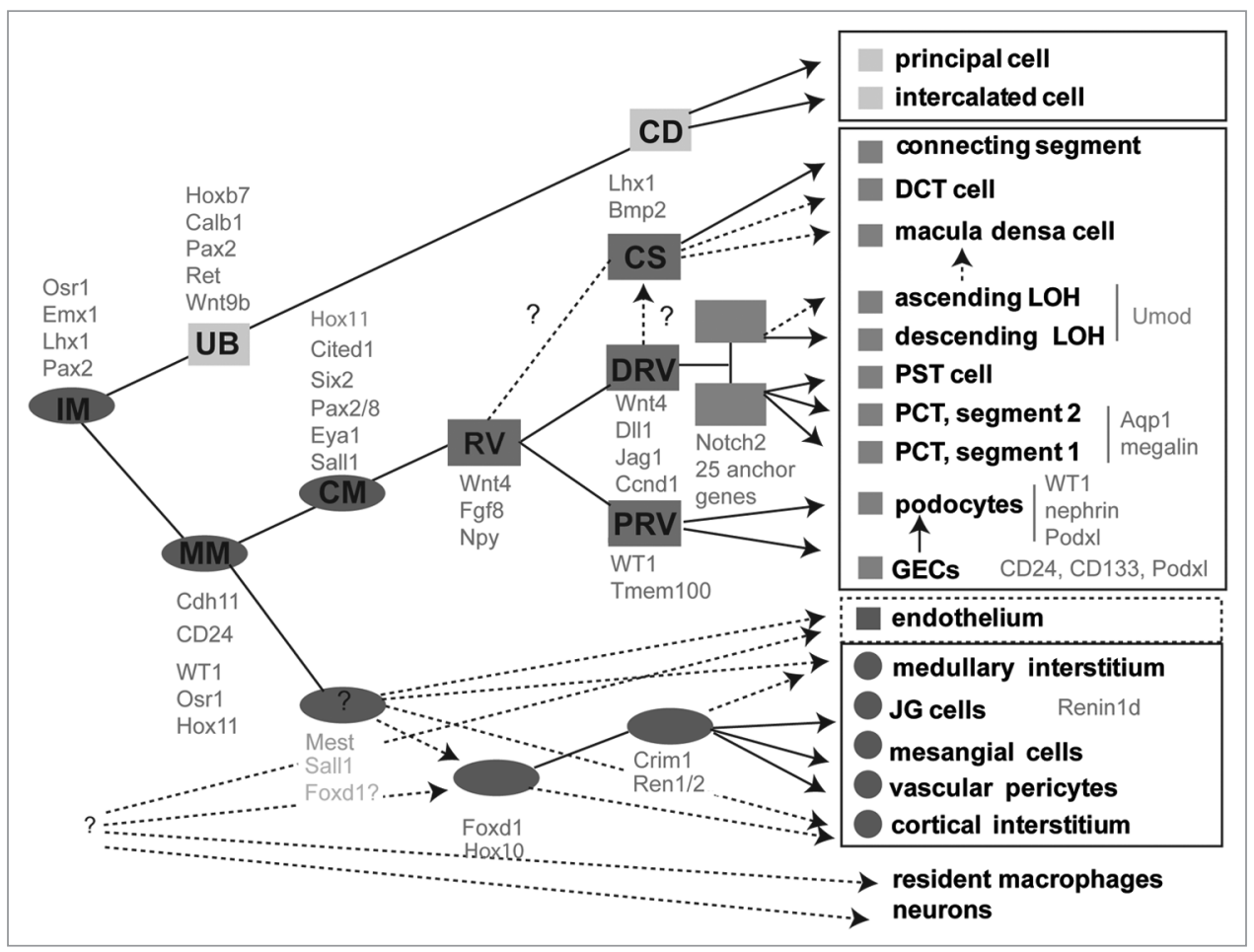

Figure 1. Incomplete lineage map of kidney development. This is based on our current understanding from the mouse. Ovals represent mesenchymal cell types. Rectangles represent epithelial cell types. Solid arrows indicate relationships that are well-supported by the current literature. Dashed lines represent likely relationships without existing lineage tracing evidence. Genes expressed at individual stages are indicated in gray at the appropriate location. Note that the Foxd $1^{+}$population gives rise to the mesangial cells, JG cells and vascular pericytes, ${ }^{57}$ but the direct origin of these cells remains controversial. ${ }^{58} \mathrm{IM}$, intermediate mesoderm; MM, metanephric mesenchyme; UB, ureteric bud; $C M$, cap mesenchyme; RV, renal vesicle; $C S$, connecting segment; DRV, distal RV; PRV, proximal RV; LOH, loop of Henle; JG, juxtaglomerular; GECs, glomerular epithelial cells; PCT, proximal convoluted tubule; PST, proximal straight tubule; DCT, distal convoluted tubule.

by Hnf4a, Hnflb, RbpJ (Notch signaling), PPARd:RxRA and COUP-TF transcription factors. We also identified an additional set of early proximal tubule genes evident from the time of formation of the Stage III nephron (capillary loop stage) (Fig. 2). While some of these genes remained confined to the proximal segment of the nephron with maturation, some showed a more extensive pattern of expression along the nephron as the loop of Henle and distal tubule became differentially distinguishable.

As the renal vesicle represents the first stage of nephron patterning and segmentation, there were very few genes that showed gene expression restricted to this stage of development without also showing expression either in the preceding cap mesenchyme or in the subsequent stages of nephron formation. ${ }^{20}$ Here, our approach was to identify a set of genes with broader spatial expression domains but whose expression was highest in the renal vesicle. ${ }^{21}$ Detailed section in situ analysis of this set of 63 genes enabled the subdivision of the renal vesicle into anatomically distinct subcompartments, revealing that as soon as epithelialization has occurred, differential fates exist within that structure. The renal vesicle can readily be divided into a distal (closest to the adjacent ureteric tip) and proximal hemisphere (furthest from the adjacent ureteric tip). Wt1 and Tmem100 showed expression restricted to the proximal renal vesicle $(R V)$, a region that will give rise to the parietal epithelial cells and podocytes of the mature glomerulus. Key members of the Bmp (Bmp2), Notch (Jag1, Dll1) and Wnt $(D k k 1, W n t 4)$ signaling pathways displayed differential distal RV expression. ${ }^{21}$ This portion of the RV also showed differential expression of cyclin D1 (Ccnd1), a marker of the $G_{1}$ phase of the cell cycle. Based on this observation, quantification of relative proliferation between distal and proximal RV was performed using the mitotic marker $\mathrm{pHH} 3$. This revealed that $73.5 \%$ of all dividing cells within the RV were located in the distal side of the structure. ${ }^{21}$

Each nephron must fuse with the ureteric epithelium to form a patent lumen, allowing urinary filtrate to exit the kidney. Little was known about this process. These analyses also revealed that coincident with immediate segmentation events, the distal side of the renal vesicle began to protrude into the adjacent ureteric epithelium. Serial triple immunofluorescent labeling and 3D reconstructions revealed that while initially formed as a ball of cells with an incomplete basement membrane, the ureteric tip epithelium loses its collagen $\mathrm{IV}^{+}$laminin ${ }^{+}$basement membrane along the distal interface with the renal vescicle from late RV stage, and here the distal RV connects with the ureteric tip. Lineage tracing verified the cap mesenchyme as the origin of the cells forming this connection segment. ${ }^{21}$ Coincident lumens were seen shortly after this time, indicating that this is an early event in nephron differentiation. 


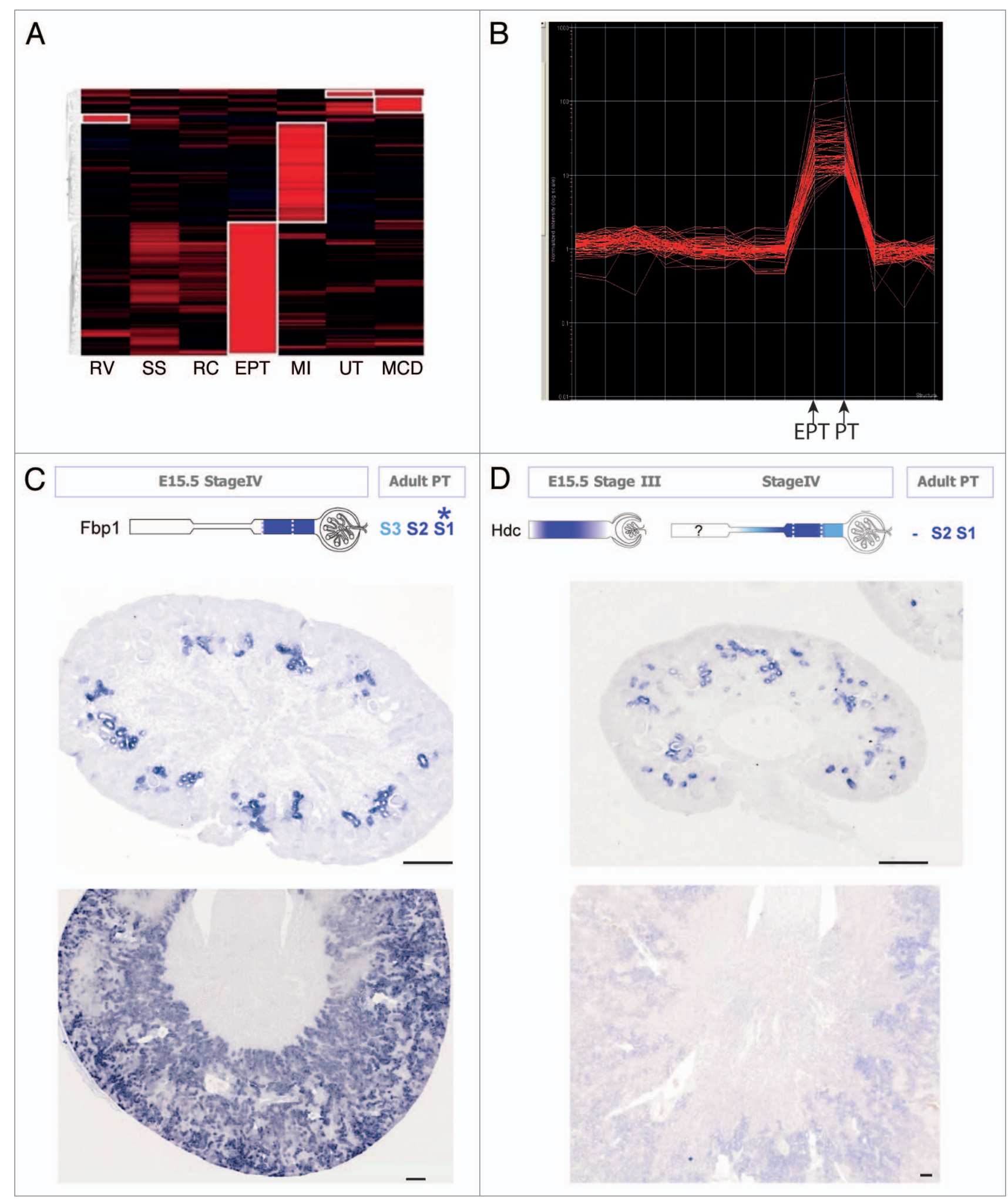

Figure 2. Identification of anchor genes for the early proximal tubule. (A) Heatmap showing genes with the greatest subcompartment specificity. Note the strong subgroup of early proximal tubule (EPT)-specific genes. (B) Intensity plot displaying those genes with the tightest specificity of expression to proximal tubule (PT)/early proximal tubule (EPT) compared with other compartments isolated in Brunskill et al. (C) Validation of specificity of expression of Fbp 1 to the proximal tubule from Stage IV of nephron development, expression in developing kidney at E15.5 (top SISH part) and location of the continued expression of this gene in adult kidney (bottom part). (D) Analysis of location of expression of Hdc during development and in adulthood with expression commencing in the earlier Stage III of nephron development (capillary loop stage; top part) and continuing in the adult proximal tubule, notably in segments S1 and S2 (bottom part). Microarray analysis courtesy of Rathi Thiagarajan and Sean Grimmond. SISH data courtesy of Bree Rumballe and Kylie Georgas and available via www.gudmap.org. 


\section{Alternatives in Postnatal Renal Repair}

Analyses such as these will extend our understanding of lineage relationships during kidney development and already appear to extend our current model by inferring that proximal RV gives rise to the podocytes and parietal epithelial cells, while the distal RV gives rise to cell types from the connecting segment to the proximal tubule. However, there is a long way to go, and a large gap remains in our understanding of intermediate stem/ progenitor cell types prior to the final differentiation of the many distinct cell types within the nephrons. Whether such intermediate progenitors exist during embryonic development and/or persist during postnatal life is unknown. What we do know is that the cap mesenchyme itself does not persist in the adult mammal. Nephron formation in humans is regarded as complete by approximately 36 weeks of gestation. Nephrogenesis in the mouse ends shortly after birth, with the remaining cap mesenchyme population committing to differentiation around postnatal day $2-3 . .^{22}$

The debate about the existence of any remaining progenitors in the postnatal kidney is very current and topical. While the kidney is not regarded as a regenerative organ, unlike the intestine, skin or blood, it has long been appreciated that this organ does have a capacity to respond to particularly acute damage. Such repair responses have been regarded as involving the proliferation of existing terminally differentiated tubular epithelial cells, ${ }^{23,24}$ allowing the recovering of denuded basement membranes. The survival of any given nephron then depends upon the efficiency of this process vs. the number of cells lost. Such repair can be elicited by a variety of insults, including ischemia, nephrotoxicity or ureteric obstruction. Transient occlusion of the renal artery (50 min) elicits immediate damage and inflammation, but this usually resolves within 7 days. In many cases, such damage can be quite extensive. In the case of unilateral ureteric obstruction, for example, it has been shown that even after a two week period of obstruction, resulting in parenchymal compression, cell necrosis and significant macrophage infiltration, release of the obstruction leads to a resolution of inflammation and restoration of tubular morphology over a 4-week period. ${ }^{25}$

While proliferation of terminally differentiated epithelial cells had been regarded as the mechanism of response to acute injury, reports have suggested that this process involves a dedifferentiation with changes in cell shape and expression of non-epithelial markers, such as vimentin. ${ }^{23}$ What is uncontested is the increase in mitotic activity within damaged tubules. ${ }^{24}$ It has also been suggested that cells within the proximal tubule rest in $G_{1}$ rather than $G_{0}$, potentially priming them for a rapid proliferative response to injury. ${ }^{24}$ Despite these data, more recently, several other possibilities have been proposed including (1) recruitment of stem cells from distant sites in the body (e.g., bone marrow), (2) the presence of a persistent stem/progenitor within the postnatal renal epithelium and/or (3) the recruitment of a stem/progenitor population from a non-epithelial compartment of the kidney. We will not discuss the literature pertaining to the recruitment of bone marrow cells to the kidney in response to injury here other than to reference that it has been extensively studied, and while this can occur, the evidence would suggest that integration of such cells into the renal parenchyma is very rare, with the repair process largely involving cell populations within the kidney itself. ${ }^{26,27}$

What evidence is there that an endogenous renal stem cell exists and participates in renal epithelial turnover/ response to injury? Over the last decades, many studies have investigated this question, seeking renal stem cell populations based on the expression of markers or functional behavior previously associated with stem cells from other organs. ${ }^{3}$ In this way, renal stem cells have been proposed to exist in the papilla, proximal tubules (both based on long-term BrdU label retention) or the interstitium (based on marker expression). We examined both the embryonic and adult murine kidney for the presence of an endogenous population of Hoescht-effluxing side population cells, ${ }^{28}$ a property previously used to enrich hematopoietic stem cells. A robust but small side population was seen in the adult kidney, and these cells displayed a number of stem cell properties, including pan-mesodermal potential in vitro. In addition, reintroduction of this population into developing chick mesonephros or mouse metanephros resulted in low frequency integration of these cells into proximal tubules, distal tubules and collecting ducts. ${ }^{28}$ Indeed, reintroduction of these cells into an adriamycin-induced renal damage model appeared to improve renal function; however, without evidence for proliferation of integrated side population cells, this was more likely to result via a pro-reparative humoral response rather than any stem cell activity. Such observations, where introduced cells appeared to ameliorate decline in renal function without evidence for a direct contribution to epithelial repair, have also been reported in response to the delivery of non-renal populations, notably, bone marrow cells. ${ }^{29,30}$ Far from providing evidence for a stem cell role in renal repair, this body of literature more accurately suggests that the endogenous response of the renal epithelium itself can be modulated via favorable humoral conditions. ${ }^{3,29,30}$

What had been lacking from the field was the prospective isolation of any cell population based upon evidence of stem cell activity. By definition, a stem cell must be capable of long-term self renewal, clonogenicity and a capacity to differentiate into one or more distinct differentiated end states. Within the developing kidney, the cap mesenchyme appeared to behave as a stem cell population, as there was evidence that no new cells entered this compartment after E11, whereas the population continued to expand in size throughout kidney development despite considerable cell loss to nephrogenesis. ${ }^{17}$ However, an inability to culture the cap mesenchyme outside the niche of the developing kidney had prevented any formal assessment of long-term self renewal or clonogenicity in vitro. Nevertheless, on the presumption that a nephron stem/progenitor population did exist in the developing kidney, we sought to establish culture conditions that would allow such in vitro characterization. The approach taken drew heavily from the neurosphere assay, developed as a method for the expansion of the neural stem cell 
population as free-floating spheres of cells capable of long-term serial passage. While the neurosphere as a whole is likely to contain only 1-3 neural stem cells, with the surrounding cells representing transitamplifying populations, serial passage of disaggregated neurospheres has been used to show the clonogenicity of the stem cell population. Using disaggregated E11.5 embryonic kidney, we screened a large number of growth factor combinations seeking conditions in which sphereforming units would arise. In this way, we demonstrated the existence of a population of cells able to form nephrospheres in minimal media containing bFGF and thrombin (Fig. 3A). ${ }^{31}$ Such spheres could be dissociated to single cells, with individual cells able to form secondary and tertiary spheres, validating a clonogenic capacity. Spheres were also able to be cultured indefinitely when supplemented with conditioned media from other sphere cultures. ${ }^{31}$ Spheres also showed multilineage potential (adipocyte, osteocyte, chrondrocyte, myotube) in vitro and retained the expression of key cap mesenchyme genes (Wt1, Sall1, Eya1, Six1, Six2, Osr1, Hoxa11, Cdh11, Gdnf) throughout culture. In contrast, such cultures did not express renal epithelial markers or markers of renal interstitium. The key question was whether these cells represented the nephron stem cells. The challenge was the lack of an assay that would address this question. For this, we developed a novel approach to determining nephron potential in which E12 embryonic kidneys were once again dissociated to a single cell suspension, mixed with sphere cells and reaggregated into a pellet that was cultured as for an explanted embryonic kidney. Extensive analyses of the renal epithelial potential of nephrosphere cells (GFP+ - or lacZ-labeled for identification) showed that these cells could, on occasion, integrate into developing nephrons
(Fig. 3B). ${ }^{31}$ While this remained a rare event, this is likely to reflect the nature of sphere cultures in that only a subfraction of any sphere represents the initiating stem cell. However, when these cells were delivered into models of adult acute renal injury (ischemia-reperfusion), cells were seen in the interstitial compartment and not seen to integrate into the renal epithelium (Fig. 3C). More importantly, the application of this technique to disaggregated postnatal kidney showed no evidence of the persistence of a postnatal stem cell population.

More recently, genetic lineage tracing was used to specifically address the question of whether there is a stem cell involved in renal repair. ${ }^{32}$ Using the Six2GFPCre mouse strain to mark all descendants of the cap mesenchyme, adult animals were subjected to acute injury models. No evidence was found for the dilution of labeling of the nephron epithelia with non-cap mesenchyme-derived cells. This suggests that repair cannot involve any cell population outside of the renal tubular epithelium itself, but does not disprove the possibility of epithelial stem/progenitors within distinct nephron segments. ${ }^{32}$ Studies into the fate of $N$ fatlc-expressing tubular epithelial cells post-damage showed that these cells gave rise to clonal patches within the re-epithelializing tubules, supporting but not proving the presence of tubular subpopulations critical for responding to tubular damage. ${ }^{33}$ Most convincing has been the data demonstrating that cells of the Bowman's capsule can acquire podocyte markers and migrate onto the vascular tuft to replace podocytes in response to injury. ${ }^{34,35}$ This may be the first evidence for an endogenous capacity for transdifferentiation within the nephron and is suggestive of a stem/progenitor response possibly in play during normal turnover of podocytes. Ronconi et al. also argue that these cells can be isolated based upon their co-expression of CD24 and CD133 and, when delivered back into renal damage models, these cells can integrate into a variety of nephron epithelia. The jury is out on whether these cells are nephron stem cells, but such examples do support the existence of renal epithelial cells with stem/progenitor capacity.

\section{The "Niche" in the Kidney during Development and Adult Life}

The blood is not a solid organ. This has assisted in the dissection of the progenitor hierarchy within this organ system. However, the hematopoietic stem cell (HSC) does reside in a bone marrow niche that may be as architecturally constrained as a solid organ. It has long been known that a second stem/progenitor stem cell type, the mesenchymal stem cell or multipotent stromal cell (MSC), residing within the bone marrow is critical for the maintenance of the HSC niche. ${ }^{36}$ These cells produce cell surface molecules critical for HSC's long-term repopulating potential and residence in/homing to the bone marrow. They also have an ability to differentiate into a variety of mesenchymal cell types themselves, including bone, fat and cartilage. ${ }^{36}$ Similarly, many solid organs also contain a niche to support a resident progenitor/stem cell, and such a niche may also include an additional stem cell population similar to the bone marrow (bm) MSC. MSC-like populations have now been isolated from most if not all organs. ${ }^{37}$ In addition, a number of studies seeking evidence for postnatal renal stem/progenitor cells have identified non-tubular mesenchymal populations with limited or no tubular potential that may represent such a population. ${ }^{38-40}$ Outside of the kidney, there is growing evidence that MSC populations frequently exist within the perivasculature where they can express pericyte markers. ${ }^{41}$

Figure 3 (See opposite page). Embryonic kidney nephrospheres and endogenous adult renal mesenchymal stem cells. (A) Nephrospheres cultured from E12.5 embryonic kidney. ${ }^{30}$ (B) Incorporation of GFP+ nephrosphere-derived cells into the tubule of a developing kidney using recombination explants culture (large arrowhead; tubule outlined with dotted line). (C) Identification of an injected nephrosphere-derived cell in the interstitium of an adult kidney (large arrowhead). (D) Colony-forming unit-fibroblastic (CFU-F) isolated from adult mouse kidney. ${ }^{42}$ (E) Differential gene expression between bone marrow-derived MSCs and renal MSCs. (F-H) Evidence for mesodermal differentiation capacity of renal MSCs into adipocytes (F), osteocytes $(\mathrm{G})$ and chrondrocytes $(\mathrm{H})$. (I and J) LacZ expression of Crim 1 in perivascular cells of the arteries (I), arterioles (I, large arrowhead) and mesangial cells (J, small arrowhead). (K) Expression of Crim1 in the papilla. (I) Model showing the decline in the nephrosphere-forming nephron progenitors toward birth and the increase in prevalence of renal MSCs after birth with respect to other developmental landmarks. Nephrosphere data courtesy of Michael Lusis. MSC data courtesy of Joan Li. Crim1 data courtesy of Lorine Wilkinson. 

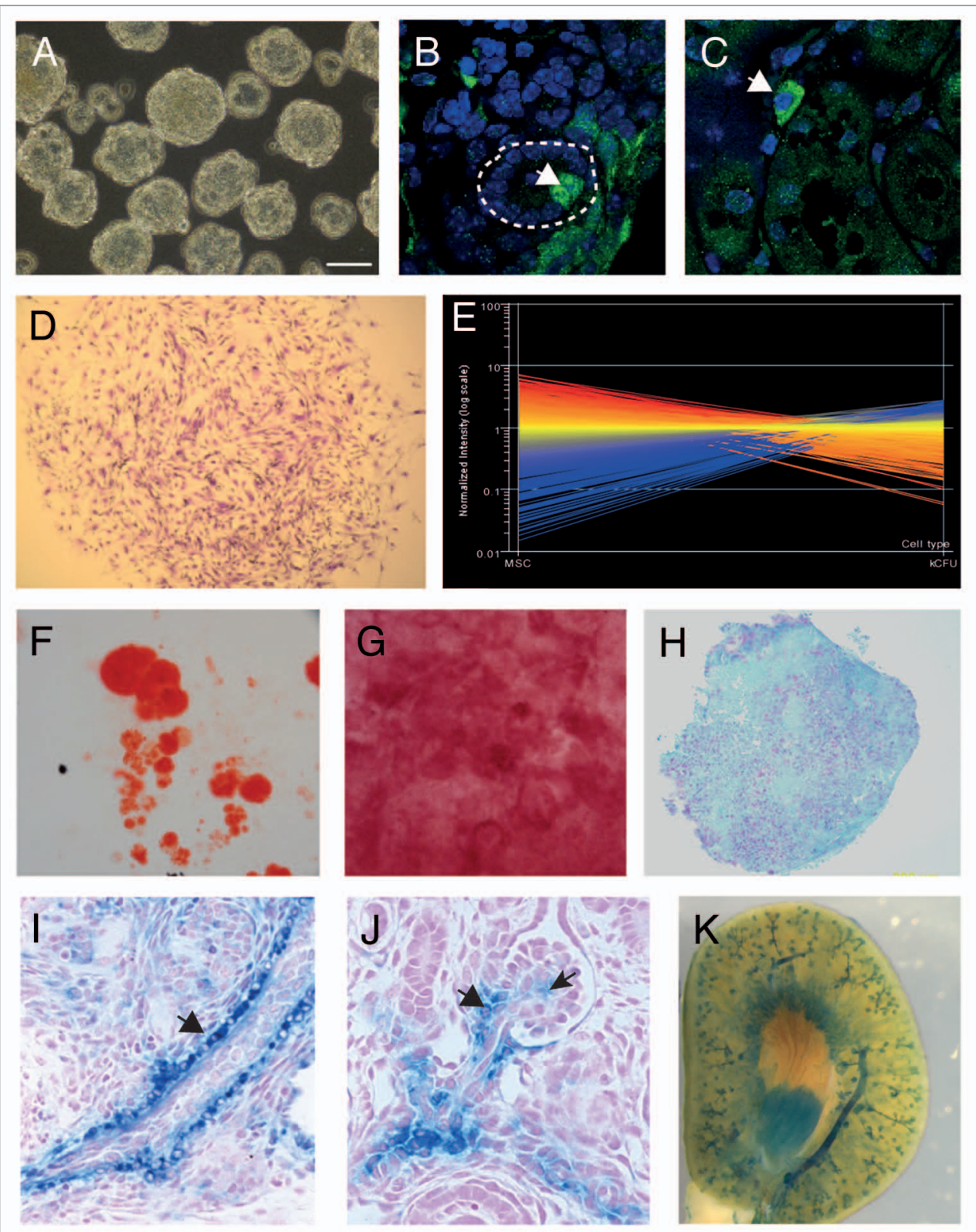

$\mathrm{L}$

\section{Birth}

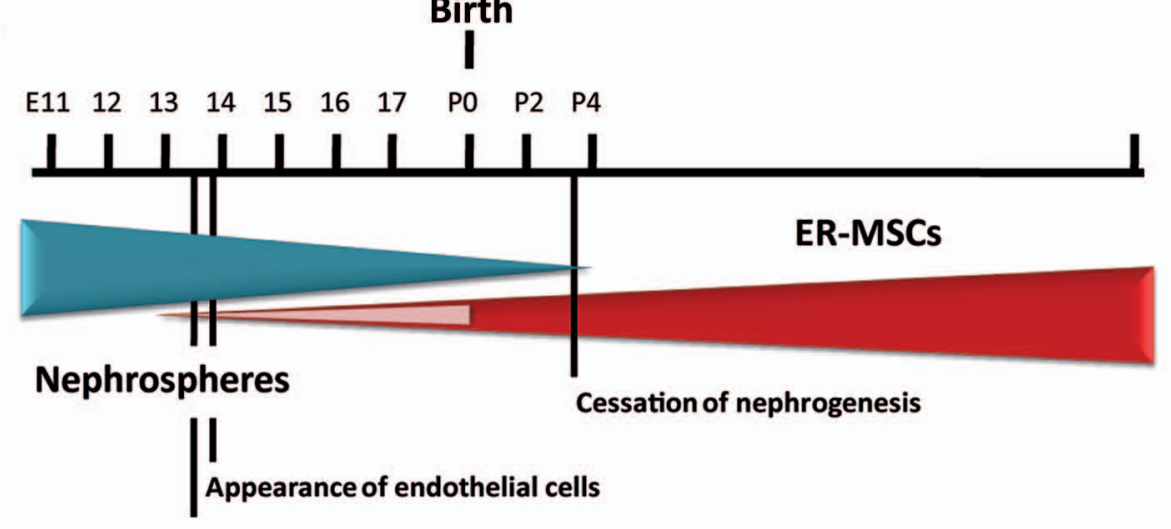

Appearance of Crim1 positive cells in renal interstitium 
The role of these cells in homeostasis is not fully characterized.

\section{The Location and Characteristics of Postnatal Renal MSCs}

On the understanding that a renal MSClike population was likely to exist and that this population may play a role in renal repair or the support of epithelial turnover in response to damage, we fractionated the adult mouse kidney seeking a subpopulation capable of long-term culture as fibroblastic colony-forming units (CFU-F). This is an assay first defined by Friedenstein for the bmMSC. ${ }^{42}$ After first depleting hematopoietic cells (CD45) and endothelial cells (CD31), whole kidney disaggregates were fractionated based upon the expression of CD24 and Sca1. Only the Sca $1^{+} \mathrm{CD} 24^{\text {lo }}$ fraction was able to form CFU-F (Fig. 3D). ${ }^{43}$ We have shown that such colonies are capable of long-term self renewal as well as differentiation along adipocytic, chrondrocytic and osteocytic pathways (Fig. 3F-H) ${ }^{43}$ In order to compare these cells with MSCs isolated from other sources, we have performed comprehensive gene expression profiling and immunophenotyping on kidney MSCs vs. those isolated from heart and bone/bone marrow. ${ }^{43}$ This revealed extensive congruence between these populations at both the gene and protein level, with all three populations expressing similar levels of Sca1, CD90.2, CD29 and CD44. Indeed, a direct comparison of immunosuppressive capacity using mixed lymphocyte reactions indicated a capacity for these cells to inhibit lymphocyte proliferation, although this was attenuated with respect to bmMSC. ${ }^{43}$ However, while the correlation between each population for gene expression was > 90\%, renal MSCs do show $>2,700$ genes with statistically significant differential expression compared with the other populations (Fig. 3E). Of note, renal MSCs show enriched expression for a number of interstitial markers (Bmp4, TGFbi, Sparc) and markers of the perivasculature (Myh11, Mlk2, Myom1, $M y o 1 b / c)$. They also show enriched expression of Crim1, a transmembrane regulator of growth factors that we have previously described within the kidney. ${ }^{44,45}$ We have previously localized the expression of
Crim1 within the perivascular compartment based on the expression of a lacZ transgene in the Crim1 knock-in mouse strain, KST264 (Fig. 3I). ${ }^{45}$ Crim1 is also expressed in the mesangial cells (Fig. 3J), which are regarded as derivatives of the pericytic compartment and in the papilla (Fig. 3K). It is interesting to note that previous studies have proposed the existence of a stem cell population within the non-tubular compartment of the papilla based on BrdU pulse chase labeling of neonatal animals. ${ }^{46}$ What is the role of these cells in the kidney? Humphreys et al. ${ }^{32}$ would argue that this non-tubular population cannot contribute to the reepithelialization of renal tubules, at least not within those compartments of the renal epithelium contributed by the Six $2^{+}$ MM. However, MSCs have been shown in many other tissues to play important humoral roles in response to damage and perhaps also in tissue homeostasis. While the cap mesenchymal stem cell population is lost after birth, in contrast, the renal MSC population is present in the adult kidney from birth but does not appear to be present in embryonic kidney (Fig. 3L). Hence, at present, its embryonic origin is not clear, but it may well have an important role in kidney homeostasis.

\section{Is All Repair Equal?}

Most of this discussion of what may occur during repair in response to injury has assumed that repair is a single process occurring uniformly and mechanistically equivalently, irrespective of the nature or duration of the insult. However, acute kidney injury can result from many distinct damage signals, including blood loss/ischemia, ureteric obstruction or toxicity. While all of these insults are likely to result in macrophage recruitment and tubular damage, it is possible that a unique facultative stem cell response exists under some conditions. Such a facultative recruitment of a cell population not generally involved in turnover has been demonstrated for both liver and pancreas. Obstruction of the pancreatic duct can result in the transdifferentiation of cells along this duct into pancreatic acinar and islet cells. ${ }^{47}$ In the liver, if the normal process of reparative hepatocyte proliferation is prevented, oval cells lining the hepatic vasculature can be recruited to elicit regeneraton. ${ }^{48}$ Whether such a facultative response occurs in response to any form of renal damage has not been extensively investigated. However, in the case of UUO, a papillary interstitial population is reported to migrate into the cortex and may play either a humoral or transdifferentiative role in the ensuing repair. ${ }^{49}$ Whether this represents a true facultative response or not, distinct patterns of gene expression do exist depending upon the damage model being examined. Having much more extensively characterized the temporospatial gene expression profile of the developing and adult kidney, the time is ripe for a more an extension of such analyses into distinct renal disease states. For example, osteopontin (Spp1), a key gene in the hematopoietic niche, ${ }^{50}$ marks the S3 segment of the proximal tubules of the developing and adult kidney at rest (Fig. 4). After UUO, this gene is strongly upregulated along the length of the nephron, with expression extending down into the papilla. In contrast, transient ischemic insult results in upregulation of $S_{p p} 1$ in a different pattern with some, but not all, nephrons upregulating this gene (Fig. 4). Of note, Spp1 is not expressed in the papilla in response to ischemia reperfusion injury.

\section{Returning to Organogenesis to Provide Other Options}

It would appear that tubular repair primarily involves a proliferative and anti-apoptotic response by the tubular epithelium, a response that is highly likely to be modulated by the response of the surrounding interstitial population. While the debate continues about whether a stem/progenitor is involved or not, recreating or ensuring maintenance of the right humoral environment for the tubular epithelium is critical. What remains to be addressed is whether this will require purified factors, delivery of MSC populations, manipulation of the endogenous interstitial compartment, including the resident renal MSCs, or direct modulation of the capacity of the tubular epithelium to respond. However, there are two other options to be explored, both 


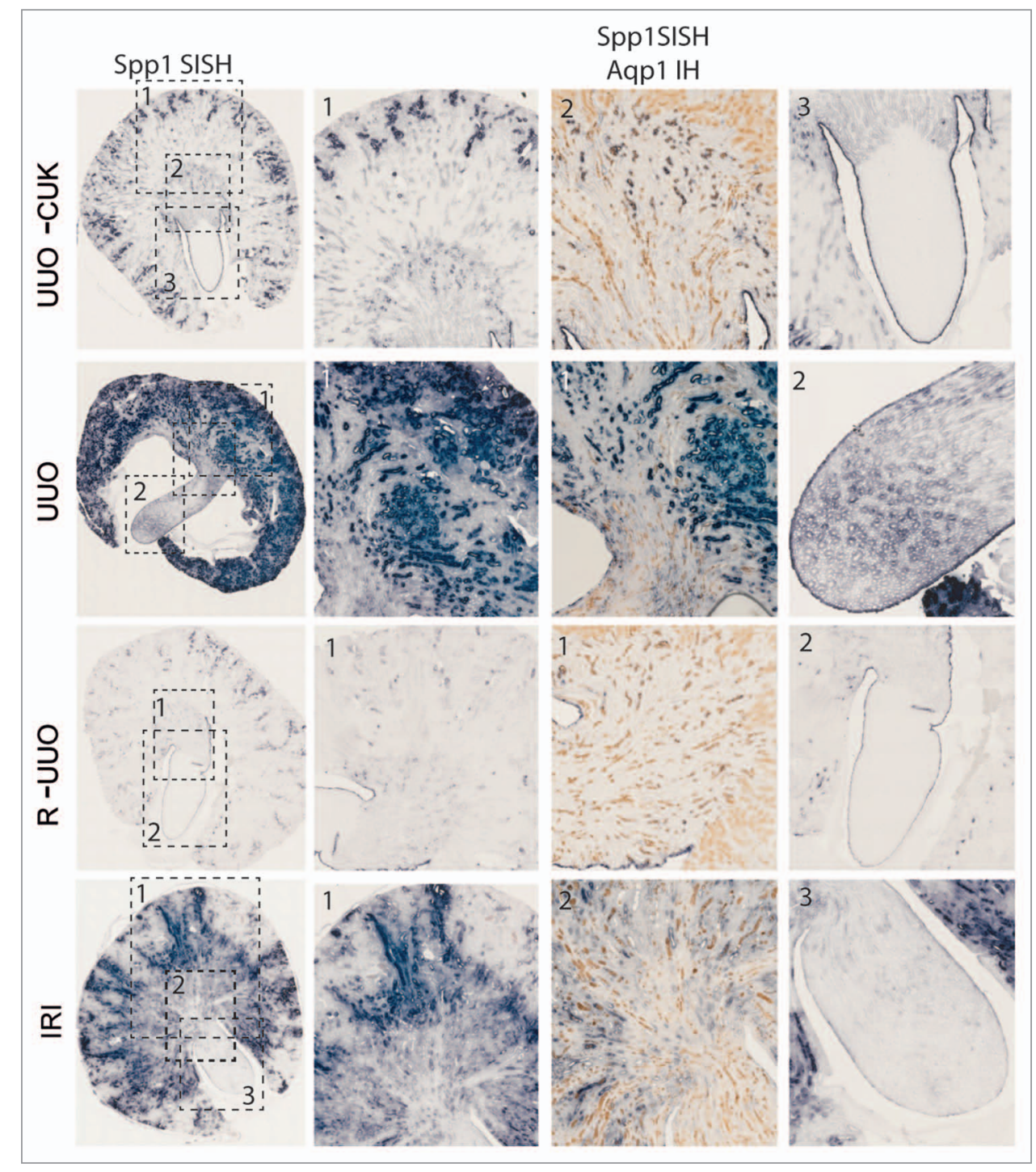

Figure 4. Section in situ hybridization for the Spp1 (osteopontin) gene in two models of renal injury: unilateral ureteric obstruction (UUO) and ischemia-reperfusion injury (IRI). UUO-CUK, contralateral kidney from animal subjected to UUO; RUUO, reversal of UUO for two weeks following 10 days of obstruction. Left parts are Spp1 SISH images of low magnification sections of adult kidneys. Dotted boxes are numbers to indicate which magnified part they refer to. Columns 2 and 4 show higher magnifications of the cortex (column 2) and papilla (column 4). Column 3 represents dual Spp1 SISH followed by immunohistochemistry for aquaporin 1 (Aqp1) to mark the proximal tubules. ${ }^{59}$ SISH data courtesy of Bree Rumballe.

of which return to our understanding of kidney development; (1) directed dedifferentiation of adult cells to a renal tubular progenitor/stem cell and (2) directed differentiation of human embryonic stem cells to a renal tubular progenitor/stem cell (Fig. 5). Waddington ${ }^{51}$ suggested many years ago that cellular differentiation could be represented as a ball rolling across a landscape where the terminal fate depended upon the valleys chosen. Since the seminal observation of Takahashi et al. ${ }^{52,53}$ that fibroblasts could be reprogrammed to a pluripotent state via the forced expression of four transcription factors, the process of reprogramming has been heavily examined. Indeed, reprogramming from one differentiated cell type to another is a growing field of interest. We know in the kidney that the cell population able to give rise to all elements of the nephron is the cap mesenchyme, ${ }^{17}$ a population that is spatially restricted and temporally transient. However, our understanding of the genes expressed by this population is now extensive, in contrast to the tubular epithelial cells to which it gives rise. We might predict that reprogramming renal tubular epithelium will require an epithelial-to-mesenchymal transition accompanied by the re-expression of key transcription factors required for cap mesenchyme survival, including Six2 (Fig. 5). Conversely, our understanding of the origin of this same progenitor population is extensive. The embryogenetic path taken to move from inner cell mass to cap mesenchyme includes mesendoderm, definitive mesoderm, intermediate mesoderm, metanephric mesenchyme and then cap mesenchyme. Stepwise recapitulation of these processes in vitro may facilitate the reinitiation of the cap mesenchymal cell state (Fig. 5). This premise that human ES (hES) cells or induced 


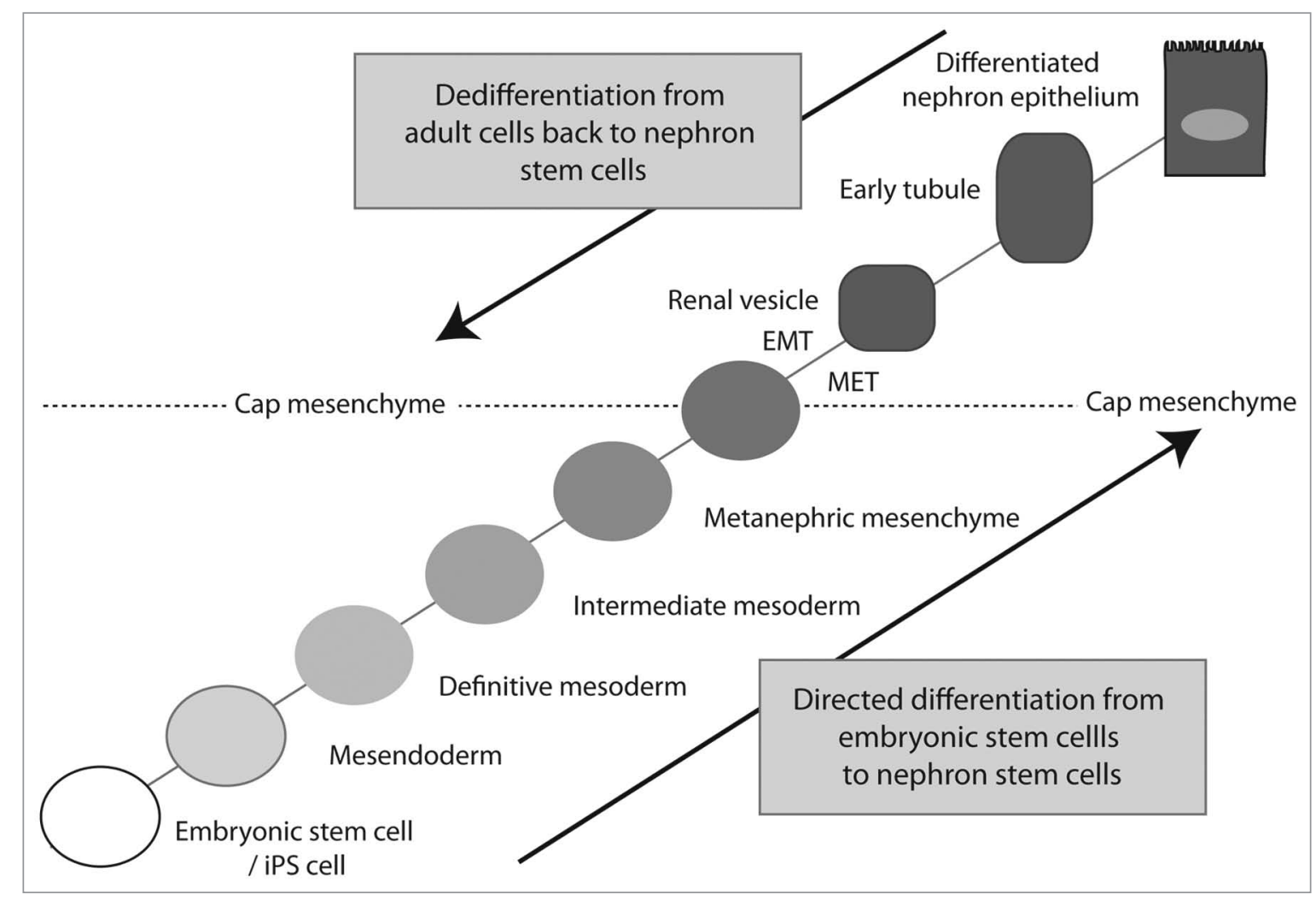

Figure 5. Approaches for the regeneration of nephron progenitor populations. Having molecularly characterized the cap mesenchyme as the source of all cells within the nephron, excepting the collecting duct, this is regarded as the nephron progenitor population. Such a population may be rederived from embryonic stem cells/iPS cells via directed differentiation through the embryological steps originally required to form the cap mesenchyme. Conversely, dedifferentiation from an adult cell type via the enforced re-expression of key transcriptional factor networks may achieve the same endpoint. Cap mesenchyme undergoes an MET to form renal vesicle. If commencing with an epithelial adult cell, one would assume an EMT would be required for the reverse to occur.

pluripotent (iPS) cells can be directed to a specific fate via the recapitulation of ontogeny in a stepwise fashion has been proposed and tested in a number of systems. Zhou et al. ${ }^{54}$ proposed a set of steps required for the directed differentiation of human ES cells to $\beta$ islet cells. Compound screening identified small molecules able to mimic key steps along this pathway, ${ }^{55}$ suggesting that the approach is feasible. A similar approach could be employed in the kidney.

\section{Conclusion}

In conclusion, the last decade has seen a significant increase in our understanding of the cellular relationships and gene expression required for normal kidney development. While there is a long way to go in understanding the processes at play and the cells involved during response to kidney injury, our increasing understanding of kidney organogenesis and lineage relationships between the embryonic cell populations and those present in the adult kidney will continue to inform us about kidney disease and repair. The hope is that this will ultimately instruct the development of regenerative approaches to improve the outcome for the patient.

\section{Questions and Answers}

Rafi Kopan Ph.D. (Professor of Developmental Biology and Medicine; Washington University School of Medicine) Great talk. It is speculated that the stem cells located in the renal papilla may originate from a Crim1 population at E14. Have you any lineage data that show whether they originate from renal or extra renal sites?

Melissa Little Ph.D. (Professor, Institute for Molecular Bioscience; University of Queensland Australia) We are developing those tools. At the moment we have a number of different Crim1 mutant mice, including a hypomorph, a total knockout and a conditional knockout. While we haven't gotten the tools yet to really answer the question of lineage of origin, I think it is an important one to answer.

Sanjay Jain M.D., Ph.D. (Assistant Professor of Medicine; Washington University School of Medicine) It is very interesting to see the data on the formation of a connection between the distal developing tubule and the ureteric bud. When the process of fusion is occurring, what molecular or cellular changes do you see in this region?

Dr. Little: We are interested in looking at changes in polarity in terms of cell division of the cells in the distal RV, whether there is apoptosis in the adjacent tip or whether there is cell migration. There is a little bit of a suggestion as to what is going on based on the gene families that we are seeing that are distally restricted. We see members of the 
BMP, notch and Wnt families in that distal side. Possibly those cells are a little bit less committed to an epithelial fate. They may remain a little bit less epithelialized and that allows them to show more of a migratory phenotype. We don't know whether that means they go through an MET and then back again, or whether they were simply less of the way through the process than the proximal side and therefore more able to keep proliferating and to migrate. Contradicting that is the fact that there is less $C d h 6$ expression in the proximal RV, and the WT1-positive cells do not become E-cadherin positive. There is a lot to understand.

Dr. Jain: Do you see Crim1 expressed in the papilla?

Dr. Little: Yes, we do. We know that Crim1 is in the perivascular niche and also in the podocytes. The cellular location in the papilla we are not sure about. Given that every CFU-F cell we isolate from our Crim1 lacZ mice is blue, we know that they are all Crim1-positive, at least in culture. It is unlikely that this is due to podocyte expression. The gene expression profiling we have done of kidney CFU-Fs agrees with that conclusion, as it suggests a perivascular location as more likely.

Scott Boyle Ph.D. (Postdoctoral Fellow in Nephrology and Washington University School of Medicine) So the Crim1-positive cells are all perivascular?

Dr. Little: No, as I was saying there is also expression in the podocytes.

Dr. Boyle: But not in tubular epithelium?

Dr. Little: Interestingly, sometimes, but possibly only in response to damage.

Dr. Boyle: Do you see LacZ-positive cells in the Crim1 reporter mouse in the tubule after injury?

Dr. Little: It seems to be expressed in the proximal tubule, and we are still interested in what that actually means. We do think that Crim1 itself responds to ischemia and upregulates in response to ischemia. With respect to the perivascular expression of Crim1 it is arterial; it is not on the venous side. However, there does seem to be expression of Crim1 in proximal tubule under certain circumstances.

Marc Hammerman (Chromalloy Professor of Renal Diseases in Medicine; Washington University School of
Medicine) I would like to ask about your UUO model. What are the cell types that regenerate?

Dr. Little: You never get more glomeruli. There is no evidence in that model that there is neo-nephrogenesis going on. I don't think there has ever been any evidence of a new nephron being formed postnatally in any model I am aware of. In this model, you do get a massive amount of tubular death, a lot of macrophage infiltration during the obstruction phase, and then you do see a lot of tubular turnover, and we see a lot of changes in the Crim1 profile. Based on a study that I haven't shown you, ${ }^{56}$ we think there is a switch in the behavior of the interstitial macrophages from an inflammatory to a reparative state, and hence, you get really strong support of the tubular epithelium to recover. However, if you have gone past the "point of no return" in any nephron, you don't get a new nephron. That dogma is sound. What we do know in this model is that even in a $10 \mathrm{~d}$ obstructed kidney, the papilla looks good. It really doesn't seem to suffer the sort of cell death and compression that the cortex does.

Dr. Hammerman: Why is the papilla spared relative to the cortex?

Dr. Little: I have no idea.

Dr. Jain: Have you looked at the effect of reducing the genetic dosage of Crim 1 on recovery from ischemic injury. For example, do animals that have only one functioning Crim 1 gene recover normally?

Dr. Little: We have not done these studies, as our interest in Crim1 started from a completely different directly direction. We were characterizing the phenotype of a hypomorph of Crim1 to look for a role for the gene in kidney development. ${ }^{45}$ This was long before we knew anything about renal MSCs. The Crim1 hypomorph has a very complex phenotype in the animal as a whole. This is published work. ${ }^{45} \mathrm{We}$ see a disruption to VEGF signaling from the podocyes, such that you get a disruption to glomerular vascular development and glomerulur cysts. ${ }^{44}$ You also get digital anomalies, lens defects as well as other defects. ${ }^{45}$ We have really focused on what that gene is doing in terms of development and haven't challenged the mice to ask how they respond to repair. However, these mice do progress spontaneously to chronic renal fibrosis. Now that we are linking the two, the Crim1 expression and CFU-F work, we are intending to ask what these cells do to repair normally and what their role is.

Feng Chen Ph.D. (Professor of Medicine; Washington University School of Medicine) I have a question about the Crim1-positive population. Foxd1 is a marker that can label stromal cells. It is speculated that stem cells or progenitor cells may come from that population. Do Foxd1 and Crim1 expressions overlap?

Dr. Little: Whether these are derived from the same cell populations, we could address using our conditional knockout, but we have not as yet. However, you don't see Crim 1 coming on in the kidney until around embryonic day 14, which is later than Foxd1, and we have not noted Foxd1 expression in the CFU-F cells. However, this is not a lineage analysis, and genes can turn on and off. Until we definitively ask that question from a lineage point of view, I can't say.

Dr. Chen: The renal progenitor population you describe early in development contributes to both glomeruli and tubule development. My impression is that tubules are repaired much more effectively than glomeruli. In many ways glomeruli are more structurally complex than tubules. Do you think that is why repair is less successful, even though glomeruli and tubules share a common progenitor?

Dr. Little: Repair in tubules and glomeruli may not use the same population of cells. Indeed, I am still not convinced that even within tubules themselves there is a stem cell. Perhaps the difference between the glomerulus and the proximal tubule is the nature of the surrounding support niche. Unlike the hematopoietic system, while there is not the requirement to have such a lot of progenitors churning out new cells postnatally in the kidney, the repair process is still likely to be controlled by a niche, in this case by the niche around the tubules or the glomeruli. The cells within the peritubular niche itself are derived at least in part from the same source as the tubules: the metanephric mesenchyme. However, some aspects of the niche may not come from metanephric mesenchyme. For example, we know for sure that there is a very intimate relationship between 
the tubules and the resident renal macrophages that wrap around the tubules, ${ }^{57}$ although not so much around the glomeruli. However, we don't believe that these macrophages are derived from metanephric mesenchyme. They arrive within the metanephric mesenchyme by E12, before most nephrons are born. In short, there is a complex peritubular niche, even in the adult kidney, that may be key to regeneration. Hence, understanding that niche is as important as anything else.

Stanley Misler M.D., Ph.D. (Associate Professor of Medicine and Cell Biology; Washington University School of Medicine) I wonder if there are links between repair of injured kidney and muscle. Satellite cells in muscle have a multinucleated structure. However, they share many electrical properties with myocytes. Although satellite cells don't have much actin or myosin synthetic capacity, they can acquire it when muscle is injured. I am wondering whether that may teach us something about renal repair? Are there comparable cells in kidney under the basal lamina?

Dr. Little: I think Ben Humphries' data argues that there isn't a cell outside the tubule that turns into a tubular cell when it is needed, at least in the models they have examined. The better comparison may be there is an equivalent of a satellite cell that is a rare population within the proximal tubule that can be induced to form tubular epithelium. Having said that, our understanding of muscle regeneration, at least in the heart, is still less than complete. There is now very complicated literature on the heart that shows that it is not just satellite cells that may be involved, but that there are other perivascular cells very similar to the CFU-F we are finding in kidney. We may have been a little bit led up the garden path by the blood system, where the progenitors and their offspring are more readily examinable without considering the niche. In a solid organ, all the cells are tightly architecturally constrained, and it is harder to identify what is niche. Hence, there is the potential for a "satellite cell"-type population in the kidney, but the histologists have never identified it. This was the case for the stem cell in the intestinal crypt as well.

\section{Acknowledgments}

M.L. is a Principal Research Fellow of the National Health and Medical Research Council. I acknowledge that this lecture presented research from past and present members of my research laboratory, including Grant Challen, Michael Lusis, Joan Li, Lorine Wilkinson, Fiona Rae, David Pennisi, Minoru Takasato, Caroline Hendry, Kylie Georgas, Han Sheng Chiu, Jessica Ineson, Norseha Suhaimi, Melissa Becroft and Bree Rumballe, and I thank them for their research efforts. I also acknowledge our collaborators within GUDMAP, notably, Sean Grimmond, Rathi Thiagarajan and Dave Tang at the University of Queensland. Aspects of this work have been supported by the National Institutes of Digestion Diabetes and Kidney, NIH (DK070136, DK070136), the NHMRC (ID45592) and the Australian Stem Cell Centre (P067, Stream 4.2) funding to M.L.

\section{Note}

Edited transcripts of research conferences sponsored by Organogenesis and the Washington University George M. O’Brien Center for Kidney Disease Research (P30 DK079333) are published in Organogenesis. These conferences cover organogenesis in all multicellular organisms including research into tissue engineering, artificial organs and organ substitutes and are participated in by faculty at Washington University School of Medicine, St. Louis, MO.

\section{References}

1. Coresh J, Selvin E, Stevens LA, Manzi J, Kusek JW, Eggers P, et al. Prevalence of chronic kidney disease in the United States. JAMA 2007; 298:2038-47; PMID:17986697; DOI:10.1001/jama.298.17.2038.

2. National Kidney \& Urologic Diseases Information Clearinghouse (NKUDIC). http://kidney.niddk. nih.gov/kudiseases/pubs/kustats/

3. Hopkins C, Li J, Rae F, Little MH. Stem cell options for kidney disease. J Pathol 2009; 217:26581; PMID:19058290; DOI:10.1002/path.2477.

4. Harding SD, Armit C, Armstrong J, Brennan J, Cheng Y, Haggarty B, et al. The GUDMAP DatabaseAn Online Resource for Genitourinary Research. Development 2011; 138:2845-53; PMID:21652655; DOI:10.1242/dev.063594.

5. McMahon AP, Aronow BJ, Davidson DR, Davies JA, Gaido KW, Grimmond S, et al. GUDMAP: the genitourinary developmental molecular anatomy project. J Am Soc Nephrol 2008; 19:667-71; PMID:18287559; DOI:10.1681/ASN.2007101078.
6. Hendry C, Rumballe BA, Moritz K, Little MH. Defining and redefining the nephron progenitor population. Pediatr Nephrol 2011; 26:1395-406; PMID:21229268; DOI:10.1007/s00467-0101750-4.

7. Kopan R, Cheng HT, Surendran K. Molecular insights into segmentation along the proximaldistal axis of the nephron. J Am Soc Nephrol 2007; 18:2014-20; PMID:17568016; DOI:10.1681/ ASN.2007040453.

8. Carroll TJ, Park JS, Hayashi S, Majumdar A, McMahon AP. Wnt9b plays a central role in the regulation of mesenchymal to epithelial transitions underlying organogenesis of the mammalian urogenital system. Dev Cell 2005; 9:283-92; PMID:16054034; DOI:10.1016/j.devcel.2005.05.016.

9. Park JS, Valerius MT, McMahon AP. Wnt/betacatenin signaling regulates nephron induction during mouse kidney development. Development 2007; 134:2533-9; PMID:17537789; DOI:10.1242/ dev.006155.

10. Stark K, Vainio S, Vassileva G, McMahon AP. Epithelial transformation of metanephric mesenchyme in the developing kidney regulated by Wnt4. Nature 1994; 372:679-83; PMID:7990960; DOI: $10.1038 / 372679 \mathrm{a} 0$.

11. Perantoni AO, Timofeeva O, Naillat F, Richman C, Pajni-Underwood S, Wilson C, et al. Inactivation of FGF8 in early mesoderm reveals an essential role in kidney development. Development 2005; 132:385971; PMID:16049111; DOI:10.1242/dev.01945.

12. Burn SF, Webb A, Berry RL, Davies JA, FerrerVaquer A, Hadjantonakis AK, et al. Calcium/NFAT signalling promotes early nephrogenesis. Dev Biol 2011; 352:288-98; PMID:21295565; DOI:10.1016/j. ydbio.2011.01.033.

13. Tanigawa S, Wang H, Yang Y, Sharma N, Tarasova $\mathrm{N}$, Ajima R, et al. Wnt4 induces nephronic tubules in metanephric mesenchyme by a non-canonical mechanism. Dev Biol 2011; 352:58-69; PMID:21256838; DOI:10.1016/j.ydbio.2011.01.012.

14. Saxen L. Organogenesis of the Kidney. In: Barlow PW, Green PB, White CC, Eds. Developmental and Cell Biology Series 19. Cambridge, UK: Cambridge University Press 1987; 19.

15. Mugford JW, Sipila P, McMahon JA, McMahon AP. Osr1 expression demarcates a multi-potent population of intermediate mesoderm that undergoes progressive restriction to an Osr1-dependent nephron progenitor compartment within the mammalian kidney. Dev Biol 2008; 324:88-98; PMID:18835385; DOI:10.1016/j.ydbio.2008.09.010.

16. Boyle S, Misfeldt A, Chandler KJ, Deal KK, Southard-Smith EM, Mortlock DP, et al. Fate mapping using Cited1-CreERT2 mice demonstrates that the cap mesenchyme contains self-renewing progenitor cells and gives rise exclusively to nephronic epithelia. Dev Biol 2008; 313:234-45; PMID:18061157; DOI:10.1016/j.ydbio.2007.10.014.

17. Kobayashi A, Valerius MT, Mugford JW, Carroll TJ, Self M, Oliver G, et al. Six 2 defines and regulates a multipotent self-renewing nephron progenitor population throughout mammalian kidney development. Cell Stem Cell 2008; 3:169-81; PMID:18682239; DOI:10.1016/j.stem.2008.05.020.

18. Self M, Lagutin OV, Bowling B, Hendrix J, Cai Y, Dressler GR, et al. Six 2 is required for suppression of nephrogenesis and progenitor renewal in the developing kidney. EMBO J 2006; 25:5214-28; PMID:17036046; DOI:10.1038/sj.emboj.7601381.

19. Brunskill EW, Aronow BJ, Georgas K, Rumballe B, Valerius MT, Aronow J, et al. Atlas of gene expression in the developing kidney at microanatomic resolution. Dev Cell 2008; 15:781-91; PMID:19000842; DOI:10.1016/j.devcel.2008.09.007. 
20. Thiagarajan RD, Georgas K, Rumballe B, Lesieur E, Chiu H, Taylor D, et al. Identification of anchor genes during kidney development defines ontological relationships, molecular subcompartments and regulatory pathways. PLoS ONE 2011; 6:17286; PMID:21386911; DOI:10.1371/journal. pone. 0017286 .

21. Georgas K, Rumballe BA, Valerius MT, Chiu HS, Thiagarajan RD, Lesieur E, et al. Analysis of early nephron patterning reveals a role for distal RV proliferation in fusion to the ureteric tip via a cap mesenchyme-derived connecting segment. Dev Biol 2009; 332:273-86; PMID:19501082; DOI:10.1016/j. ydbio.2009.05.578.

22. Rumballe B, Georgas KM, Combes AN, Ju AL, Gilbert T, Little MH. Nephron formation adopts a novel spatial topology at cessation of nephrogenesis. Dev Biol 2011; In Press.

23. Witzgall R, Brown D, Schwarz C, Bonventre JV. Localization of proliferating cell nuclear antigen, vimentin, c-Fos and clusterin in the postischemic kidney. Evidence for a heterogenous genetic response among nephron segments, and a large pool of mitotically active and dedifferentiated cells. J Clin Invest 1994; 93:2175-88; PMID:7910173; DOI:10.1172/ JCI117214.

24. Vogetseder A, Picard N, Gaspert A, Walch M, Kaissling B, Le Hir M. Proliferation capacity of the renal proximal tubule involves the bulk of differentiated epithelial cells. Am J Physiol Cell Physiol 2008; 294:22-8; PMID:17913845; DOI:10.1152/ ajpcell.00227.2007.

25. Cochrane AL, Kett MM, Samuel CS, Campanale NV, Anderson WP, Hume DA, et al. Renal structural and functional repair in a mouse model of reversal of ureteral obstruction. J Am Soc Nephrol 2005; 16:3623-30; PMID:16221872; DOI:10.1681/ ASN.2004090771.

26. Lin F, Moran A, Igarashi P. Intrarenal cells, not bone marrow-derived cells, are the major source for regeneration in postischemic kidney. J Clin Invest 2005; 115:1756-64; PMID:16007252; DOI:10.1172/ JCI23015.

27. Duffield JS, Park KM, Hsiao LL, Kelley VR, Scadden DT, Ichimura $\mathrm{T}$, et al. Restoration of tubular epithelial cells during repair of the postischemic kidney occurs independently of bone marrowderived stem cells. J Clin Invest 2005; 115:1743-55; PMID:16007251; DOI:10.1172/JCI22593.

28. Challen GA, Bertoncello I, Deane JA, Ricardo SD, Little MH. Kidney side population reveals multilineage potential and renal functional capacity but also cellular heterogeneity. J Am Soc Nephrol 2006; 17:1896-912; PMID:16707564; DOI:10.1681/ ASN.2005111228.

29. Villanueva S, Ewertz E, Carrión F, Tapia A, Vergara C, Céspedes C, et al. Mesenchymal stem cell injection ameliorates chronic renal failure in a rat model. Clin Sci (Lond) 2011; 121:489-99; PMID:21675962; DOI:10.1042/CS20110108.

30. Tögel F, Hu Z, Weiss K, Isaac J, Lange C, Westenfelder C. Administered mesenchymal stem cells protect against ischemic acute renal failure through differentiation-independent mechanisms. Am J Physiol Renal Physiol 2005; 289:31-42; PMID:15713913; DOI:10.1152/ajprenal.00007.2005.

31. Lusis M, Ineson J, Li J, Little MH. Isolation and culture of metanephric mesenchyme-derived nephrospheres reinforces evidence that embryonic renal progenitors are multipotent and exhaust during cessation of nephron formation. Stem Cell Res (Amst) 2010; 5:23-39; DOI:10.1016/j.scr.2010.03.003.

32. Humphreys BD, Valerius MT, Kobayashi A, Mugford JW, Soeung S, Duffield JS, et al. Intrinsic epithelial cells repair the kidney after injury. Cell Stem Cell 2008; 2:284-91; PMID:18371453; DOI:10.1016/j. stem.2008.01.014.
33. Langworthy M, Zhou B, de Caestecker M, Moeckel G, Baldwin HS. NFATc1 identifies a population of proximal tubule cell progenitors. J Am Soc Nephrol 2009; 20:311-21; PMID:19118153; DOI:10.1681/ ASN.2008010094.

34. Ronconi E, Sagrinati C, Angelotti ML, Lazzeri E, Mazzinghi B, Ballerini L, et al. Regeneration of glomerular podocytes by human renal progenitors. J Am Soc Nephrol 2009; 20:322-32; PMID:19092120; DOI:10.1681/ASN.2008070709.

35. Appel D, Kershaw DB, Smeets B, Yuan G, Fuss A, Frye B, et al. Recruitment of podocytes from glomerular parietal epithelial cells. J Am Soc Nephro 2009; 20:333-43; PMID:19092119; DOI:10.1681/ ASN.2008070795.

36. Pittenger MF, Mackay AM, Beck SC, Jaiswal RK, Douglas R, Mosca JD, et al. Multilineage potential of adult human mesenchymal stem cells. Science 1999; 284:143-7; PMID:10102814; DOI:10.1126/ science.284.5411.143.

37. da Silva Meirelles L, Chagastelles PC, Nardi NB. Mesenchymal stem cells reside in virtually all postnatal organs and tissues. J Cell Sci 2006; 119:220413; PMID:16684817; DOI:10.1242/jcs.02932.

38. Plotkin MD, Goligorsky MS. Mesenchymal cells from adult kidney support angiogenesis and differentiate into multiple interstitial cell types including erythropoietin producing fibroblasts. Am J Physiol Renal Physiol 2006; 291:902-12; PMID:16622175; DOI:10.1152/ajprenal.00396.2005.

39. Gupta S, Verfaillie C, Chmielewski D, Kren S, Eidman $\mathrm{K}$, Connaire J, et al. Isolation and characterization of kidney-derived stem cells. J Am Soc Nephrol 2006; 17:3028-40; PMID:16988061; DOI:10.1681/ASN.2006030275.

40. Dekel B, Zangi L, Shezen E, Reich-Zeliger S, Eventov-Friedman S, Katchman H, et al. Isolation and characterization of nontubular sca-1 ${ }^{+}$lin multipotent stem/progenitor cells from adult mouse kidney. J Am Soc Nephrol 2006; 17:3300-14; PMID:17093069; DOI:10.1681/ASN.2005020195.

41. Crisan M, Yap S, Casteilla L, Chen CW, Corselli M, Park TS, et al. A perivascular origin for mesenchyma stem cells in multiple human organs. Cell Stem Cell 2008; 3:301-13; PMID:18786417; DOI:10.1016/j. stem.2008.07.003.

42. Friedenstein AJ, Deriglasova UF, Kulagina NN, Panasuk AF, Rudakowa SF, Luria EA, et al. Precursors for fibroblasts in different populations of hematopoietic cells as detected by the in vitro colony assay method. Exp Hematol 1974; 2:83-92. PMID:4455512.

43. Pelekanos RA, Li J, Gongora M, Chandrakanthan V, Scown J, Suhaimi N, et al. Comprehensive transcriptome and immunophenotype analysis of renal and cardiac MSC-like populations supports strong congruence with bone marrow MSC despite maintenance of distinct identities. Stem Cell Res (Amst) 2011; In press; DOI:10.1016/j.scr.2011.08.003.

44. Wilkinson L, Gilbert T, Kinna G, Ruta LA, Pennisi D, Kett M, et al. Crim1KST264/KST264 mice implicate Crim1 in the regulation of vascular endothelial growth factor-A activity during glomerular vascular development. J Am Soc Nephrol 2007; 18:1697-708; PMID:17460146; DOI:10.1681/ ASN.2006091012.

45. Pennisi DJ, Wilkinson L, Kolle G, Sohaskey ML, Gillinder K, Piper MJ, et al. Crim1KST264/ KST264 mice display a disruption of the Crim1 gene resulting in perinatal lethality with defects in multiple organ systems. Dev Dyn 2007; 236:502-11; PMID:17106887; DOI:10.1002/dvdy.21015.
46. Oliver JA, Maarouf O, Cheema FH, Martens TP, Al-Awqati Q. The renal papilla is a niche for adult kidney stem cells. J Clin Invest 2004; 114:795-804; PMID: 15372103.

47. Xu X, D’Hoker J, Stangé G, Bonné S, De Leu N, Xiao X, et al. Beta cells can be generated from endogenous progenitors in injured adult mouse pancreas. Cell 2008; 132:197-207; PMID:18243096; DOI:10.1016/j.cell.2007.12.015.

48. Cantz T, Manns MP, Ott M. Stem cells in liver regeneration and therapy. Cell Tissue Res 2008; 331:271 82; PMID:17901986; DOI:10.1007/s00441-0070483-6.

49. Oliver JA, Klinakis A, Cheema FH, Friedlander J, Sampogna RV, Martens TP, et al. Proliferation and migration of label-retaining cells of the kidney papilla. J Am Soc Nephrol 2009; 20:2315-27; PMID:19762493; DOI:10.1681/ASN.2008111203.

50. Haylock DN, Nilsson SK. Osteopontin: a bridge between bone and blood. $\mathrm{Br}$ J Haematol 2006; 134:467-74; PMID:16848793; DOI:10.1111/j.13652141.2006.06218.x.

51. Waddington $\mathrm{CH}$. Organisers \& genes. Cambridge: Cambridge University Press 1994.

52. Takahashi K, Yamanaka S. Induction of pluripotent stem cells from mouse embryonic and adult fibroblast cultures by defined factors. Cell 2006; 126:663-76; PMID:16904174; DOI:10.1016/j.cell.2006.07.024.

53. Takahashi K, Tanabe K, Ohnuki M, Narita M, Ichisaka T, Tomoda K, et al. Induction of pluripotent stem cells from adult human fibroblasts by defined factors. Cell 2007; 131:861-72; PMID:18035408; DOI:10.1016/j.cell.2007.11.019.

54. Zhou Q, Melton DA. Pathways to new beta cells. Cold Spring Harb Symp Quant Biol 2008; 73:175-81; PMID:19478324; DOI:10.1101/sqb.2008.72.002.

55. Chen S, Borowiak M, Fox JL, Maehr R, Osafune K, Davidow L, et al. A small molecule that directs differentiation of human ESCs into the pancreatic lineage. Nat Chem Biol 2009; 5:258-65; PMID:19287398; DOI:10.1038/nchembio.154.

56. Alikhan MA, Jones CV, Williams TM, Beckhouse AG, Fletcher AL, Kett MM, et al. ColonyStimulating Factor-1 Promotes Kidney Growth and Repair via Alteration of Macrophage Responses. Am J Pathol 2011; 179:1243-56; PMID:21762674; DOI:10.1016/j.ajpath.2011.05.037.

57. Rae F, Woods K, Sasmono T, Campanale N, Taylor D, Ovchinnikov D, et al. Characterisation and trophic functions of murine embryonic macrophages based upon the use of a CSF-1R-EGFP transgene reporter. Dev Biol 2007; 308:232-46; PMID:17597598; DOI:10.1016/j.ydbio.2007.05.027.

58. Humphreys BD, Lin SL, Kobayashi A, Hudson TE, Nowlin BT, Bonventre JV, et al. Fate tracing reveals the pericyte and not epithelial origin of myofibroblasts in kidney fibrosis. Am J Pathol 2010; 176:85-97; PMID:20008127; DOI:10.2353/ ajpath.2010.090517.

59. Yallowitz AR, Hrycaj SM, Short KM, Smyth IM, Wellik DM. Hox10 genes function in kidney development in the differentiation and integration of the cortical stroma. PLoS ONE 2011; 6:23410; PMID:21858105; DOI:10.1371/journal. pone. 0023410

60. Rumballe B, Georgas K, Little MH. Highthroughput paraffin section in situ hybridization and dual immunohistochemistry on mouse tissues. $\mathrm{CSH}$ Protoc 2008. 